\title{
Is emotional dysregulation part of the psychopathology of ADHD in adults?
}

\author{
Salvatore Corbisiero $\cdot$ Rolf-Dieter Stieglitz • \\ Wolfgang Retz $\cdot$ Michael Rösler
}

Received: 15 August 2012/ Accepted: 20 November 2012/Published online: 4 December 2012

(C) Springer-Verlag Wien 2012

\begin{abstract}
Attention-deficit hyperactivity disorder is a common condition in adulthood. The disorder is characterized by symptoms of inattention, hyperactivity, and impulsivity. Alongside these symptoms, it is discussed whether symptoms of emotional dysregulation could add additional and better description of the psychopathology of ADHD. Neither the current ICD-10 and DSM-IV nor the upcoming DSM-5 includes symptoms of emotional dysregulation as a core aspect of ADHD. Several authors (e.g., Wender 1995) describe adult ADHD in a more differentiated way and propose concepts of the disorder that consider the subjective experiences of the adult patient by introducing the symptomatology of emotional symptoms. Empirical studies attest this dimension sufficient reliability and validity. Symptoms of emotional dysregulation are definable and seem to be distinct factors of the psychopathology of adult ADHD. Pharmacological and psychotherapeutic interventions help to alleviate this type of symptoms. This review attests a decisive role to the emotional symptoms in the ADHD symptomatology, which should be taken in serious consideration by future research.
\end{abstract}

Keywords ADHD in adults - Emotional dysregulation . Wender-Reimherr Adult Attention Disorder Rating Scale . ADHD psychopathology

S. Corbisiero $(\square) \cdot$ R.-D. Stieglitz

University of Basel Psychiatric Clinics, Wilhelm Klein-Strasse

27, 4012 Basel, Switzerland

e-mail: salvatore.corbisiero@upkbs.ch

R.-D. Stieglitz

e-mail: rolf-dieter.stieglitz@upkbs.ch

W. Retz $\cdot$ M. Rösler

Saarland University Hospital, Homburg, Saar, Germany

\section{Introduction}

Attention-deficit hyperactivity disorder (ADHD) in adulthood is a relatively new disorder. Until recently, it was still presumed that children would grow out of this symptomatology at the latest upon termination of puberty. Now, however, there is mounting evidence that the disorder can persist into adulthood (Barkley 2006; Mannuzza et al. 1993; Murphy and Gordon 2006; Schmidt and Petermann 2008; Stieglitz et al. 2012). Epidemiological analyses have shown that during adulthood the symptomatology can be found as full or partial syndrome in $50 \%$ of patients (Faraone et al. 2006). Data from the World Health Organization (WHO) found a transnational prevalence of $3.4 \%$ for ADHD in adults (Fayyad et al. 2007). The diagnosis of the disorder is a clinical one and represents the first challenge that has to be taken.

\section{Classification of adult ADHD}

The classification of adult ADHD follows the same principles as in child and adolescent psychiatry (Stieglitz and Rösler 2006). The 18 diagnostic criteria of DSM-IV or ICD10 are classified in three major symptom domains of inattention, hyperactivity, and impulsivity. While for a diagnosis based on ICD-10 a specific number of symptoms from all three domains is needed, DSM-IV differentiates between subtypes - the predominantly inattentive (314.00) - versus the hyperactive-impulsive type (314.01), so that the corresponding symptoms suffice. Only in the combined type (314.01), the criteria for all three domains have to be fulfilled.

Besides the critique of the unsatisfactory picture representation of the symptomatology of the adult ADHD in the diagnostic criteria, there is an increasing discussion 
whether the tripartition inattention, hyperactivity, and impulsivity is an adequate description of the full nature of the adult ADHD (cf. e.g., Gibbins and Weiss 2007). On the one hand, studies have demonstrated that these three psychopathological dimensions are not stable over time (Biederman et al. 2000; Faraone et al. 2006); on the other hand, it is discussed whether further symptom domains can be included in the description of the pathology of ADHD in adulthood (Barkley and Murphy 2006). Another main concern of these debates is the question to which extent impairments ought to be seen as part of the area of affectivity (Barkley and Murphy 2010). Thus, phenomena of emotional dysregulation moved into the centre of attention.

The upcoming new DSM-5 conception of ADHD will introduce many new diagnostic aspects, particularly for adult ADHD. But there will be no change regarding the three classical symptom domains of inattention, hyperactivity, and impulsivity. Emotional dysregulation is not planed to be included in the set of diagnostic criteria for ADHD, as it is not seen as part of its core psychopathology. For the assessment of emotional symptoms, the separate category of "temper dysregulation with dysphoria" has been considered in the chapter of disruptive disorders (www.dsm5.org). However, there are different concepts of the disorder that take into account the subjective experiences of the adult patient. Figure 1 introduces the concepts of Wender (1995; cf. also Rösler et al. 2008a, b), Brown (1996), Conners et al. (1999). As Fig. 1 shows that the proposals of the various authors are different, but partly overlapping with the central constructs of the disorder. With regard to the question of the significance of emotional dysregulation in adult ADHD, above all, the analyses of Paul H. Wender (1995) are of outstanding importance. In Fig 2, the conceptualization of the ADHD symptomatology of Wender and their relation to ICD-10 or DSM-IV/DSM5, Brown, and Conners are demonstrated. According to the Utah Criteria for ADHD in adults, the domain impulsivity, in contrast to ICD-10 and DSM-IV/DSM-5, is not counted among the core symptoms of ADHD, but only inattention and hyperactivity, which are furthermore specified with the aspect of restlessness. Impulsivity is, like disorganization and the domain emotional dysregulation, only an additional symptom domain. Emotional dysregulation is defined by three subscales referring to temper control, affective lability, and emotional overreactivity (synonym: stress intolerance). Temper control refers to "feelings of irritability and frequent outbursts of short duration", affective lability is associated with short and unpredictable "shifts from normal mood to depression or mild excitement", and emotional overreactivity refers to "a diminished ability to handle typical life stresses, resulting in frequent feelings of being hassled and overwhelmed" (Reimherr et al. 2005, p. 125). While the dimensions hyperactivity and impulsivity are not part of the ADHD concept of Brown, DSMIV and DSM-5 do not consider the emotional spectrum of the disorder. However, the Conners' concept proposes two domains impulsivity/emotional lability and problems with self-concept as part of the emotional components of adult ADHD; Brown's model delineates the domain affective interference as being an emotional component of the disorder as well.

\section{Relevance of emotional dysregulation in adults}

The significance of the conceptualization of emotional dysregulation as a part of the symptomatology of ADHD is justified from different perspectives: clinical, theoretical, and empirical: clinical because patients' statements time and again suggest that the classic triad of ADHD symptoms, inattention, hyperactivity, and impulsivity, is not sufficient to adequately describe the psychopathological facets and functional impairment of patients suffering from adult ADHD combined type. These patients consistently report on mood swings, which significantly change more rapidly than in affective disorders; that is, they may be saddened for the day, or there may be several mood swings a day, from elated to death. Patients have many problems to
Fig. 1 Dimensionality of ADHD: different concepts

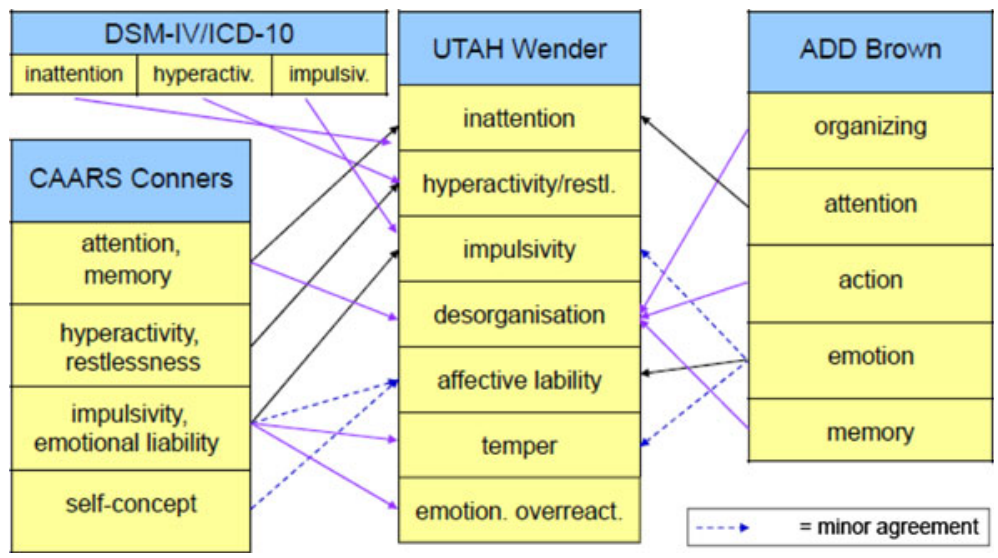


Fig. 2 Structure of the Wender-Reimherr Adult Attention Disorder Rating Scale (WRAADDS)

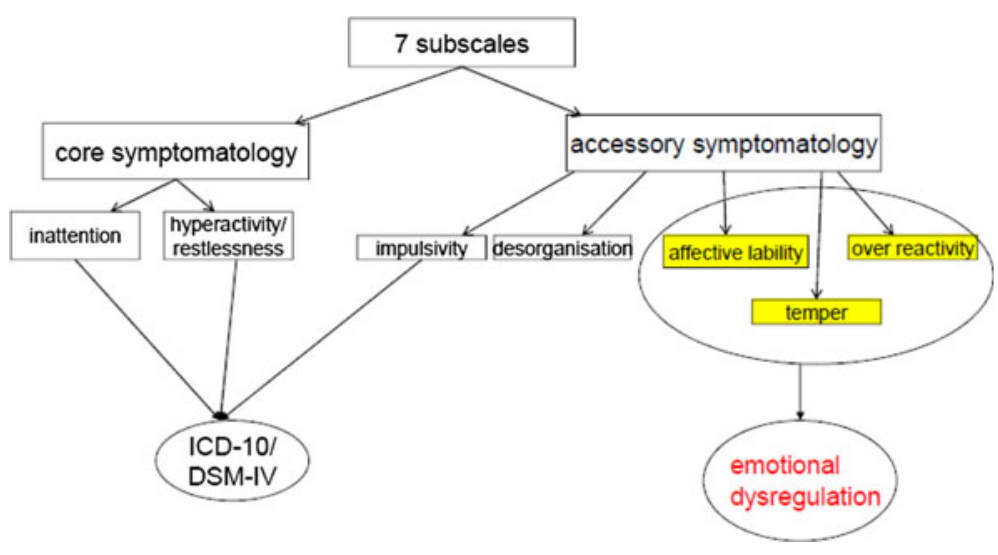

deal with in stressful situations and are frequently and quickly irritated by little things in everyday life (e.g. to get angry fast). This is consistent with the theoretical findings: it could be shown that there is an association of the classical ADHD symptoms not only with cognitive deficits and neuroanatomical substrates, but also with mood variability (cf. Skirrow et al. 2009). Of particular importance is, moreover, the mounting empirical evidence for the significance of symptoms of emotional dysregulation.

The aim of this article is to outline the concept of emotional dysregulation in adult ADHD and to ascertain the potential importance of this topic. Therefore, explicitly those studies are explored that furnish empirical evidence for emotional dysregulation and take in consideration these symptoms in the concept of ADHD in adulthood. Particularly, the reliability and the validity of the emotional symptoms were investigated.

\section{Empirical evidence for emotional dysregulation in adult ADHD}

The following review centres in detail on:

- Reliability

- Internal consistency

- Interrater reliability

- Validity

- Descriptive validity

- Factorial validity

- Convergent validity

- Divergent validity

- Measurement of change

- Treatment response

This is exemplified first of all by studies with the Wender-Reimherr Adult Attention Disorder Rating Scale (WRAADDS; Wender 1995; Rösler et al. 2008a, b), which has been designed according to the Utah Criteria for adult ADHD. The WRAADDS assesses the domain of emotional dysregulation as outlined above using three subscales: affective lability, temper control, and emotional overreactivity (cf. Fig. 2).

\section{Reliability}

In a summary of the psychometric properties of the Utah Criteria, Reimherr et al. (2003) identified a Cronbach's $\alpha \geq .80$ for the seven subscales of the WRAADDS. For the subscales affective lability, temper control, and emotional overreactivity that compose the domain emotional dysregulation, Rösler et al. (2008a) found in a study comparing different systems for the diagnosis of ADHD satisfactory reliability (Cronbach's $\alpha$ of .69, .68 and .61, respectively). Corbisiero et al. (2010) found in their research good reliability with a Cronbach's $\alpha$ of $.80, .76$, and .78 , respectively.

While Rösler et al. (2008a) determined the interrater reliability of the WRAADDS at the level of the diagnosis (Cohen's Kappa $\kappa$ of 1.0), Corbisiero et al. (2010) explored it at the level of the items ( 26 of 28 items were over $\kappa .60$; 12 of 28 items even over $\kappa .81$ ). Especially the coefficients of the subscale temper control showed a very good interrater reliability $(\kappa>.88)$.

\section{Descriptive validity}

Descriptive validity refers to the differentiability and the frequency of emotional dysregulation found in the analysed studies. In two psychopharmacological studies of Reimherr et al. $(2005,2007), 32 \%(N=529)$ and over $80 \%$ $(N=47)$ of all included patients met the criteria for emotional dysregulation, respectively, defined by the cluster of emotional symptoms on the WRAADDS. Robison et al. (2008) used also the concept of emotional dysregulation derived from the Utah Criteria to analyse, 
among other things, gender differences in baseline attributes. $37 \%$ of the female and $29 \%$ of the male subjects had elevations on these symptoms. In a sample of consecutive patients $(N=168)$, Rösler et al. (2008a) demonstrated that 16 of 28 WRAADDS items were identified in at least $90 \%$ of all patients, four of these items being part of the domain of emotional dysregulation. These symptoms, although numerically not that relevant, seem to have a significant impact. In another analysis, Rösler (2011) found that eight of the 19 most frequent symptoms of ADHD with a prevalence of at least $80 \%$ of patients $(N=479)$ are emotional symptoms. Reimherr et al. (2010) could identify in a genetic study $73 \%$ of subjects $(n=53 ; N=80)$ with emotional dysregulation in connection with adult ADHD. In a sample of 540 patients assessed with the WRAADDS, Corbisiero et al. (2010) describe all three subscales inherent to the emotional dysregulation symptomatic. The majority of the diagnosed persons with ADHD $(n=99$, $34.1 \%$ ) showed impairments in all seven scales of the WRAADDS. First of all, the subscale temper control was numerously represented. Finally, in the study of Robison et al. (2010), $72 \%(n=98 ; N=136)$ of the sample were categorized as ADHD patients with emotional dysregulation.

\section{Factorial validity}

The dimensionality of the WRAADDS and its subscales has already been analysed as well. Reimherr et al. (2003) stated that factor analysis showed all seven areas to be closely related; nevertheless, three factors could be separated: symptoms of emotional dysregulation, inattentional/ disorganizational and hyperactive/impulsive symptoms. Furthermore, Rösler et al. (2008a, b) examined the factor structure of the ADHD psychopathology represented by the seven WRAADDS subscales with the three subscales of the ADHD Self-Report (ADHD-SR; Rösler et al. 2004). They found a two-factor solution explaining for $63 \%$ of the variance, so that the subscales inherent to emotional dysregulation were designated as two different factors. Factor 1 comprised, besides affective lability, impulsivity, hyperactivity, and temper control; factor 2 on the contrary consisted of emotional overreactivity, inattention, and disorganization. Corbisiero et al. (2010) conducted a principal component analyses with varimax rotation to determine the dimensionality of the WRAADDS. The variance of the seven-factorial solution was $57.7 \%$. Emotional dysregulation with its components affective lability $(9.1 \%)$, temper control $(7.9 \%)$, and emotional overreactivity $(7.8 \%)$ explained $24.8 \%$ of the variance. Furthermore, the analyses demonstrated that it was possible to isolate the emotional dysregulation symptoms from the other aspects of ADHD in adulthood, meaning that the three domains of emotional dysregulation can easily be distinguished from other domains of the ADHD symptomatology (Stieglitz 2011).

\section{Convergent validity}

One of the most important aspects within the evaluation of instruments for the assessment of psychopathological ADHD traits refers to the convergent validity of the different concepts. This parameter tests whether constructs that should be related are in fact related. The correspondence of measures of similar constructs is high and low to measures that assess dissimilar constructs. The convergent validity of the WRAADDS subscales was examined in several studies (cf. e.g. Corbisiero et al. 2010; Rösler et al. 2008a, b). In the majority of the cases, the scales of the WRAADDS were correlated with Conners' Adult ADHD Rating Scale for Raters (CAARS-R; Conners et al. 1999), ADHS-SR, and Attention Deficit Hyperactivity Disorder Diagnostic Checklist (ADHD-DC; Rösler et al. 2004), for example self- and observer-rating scales. The correlations were moderate to strong. A few studies explicitly examined the domain emotional dysregulation of the WRAADDS: Reimherr et al. (2005) calculated substantial correlations between the WRAADDS emotional dysregulation domain and the subscales of the CAARS-R (attention $r=.48$ and hyperactivity/impulsivity $r=.48$ ). Reimherr et al. (2010) found a significant relationship between the three WRAADDS factors attention + disorganization, hyperactivity + impulsivity, and emotional dysregulation. Emotional dysregulation correlated with attention + disorganization $(r=.38, n=136, p<.001)$ and hyperactivity + impulsivity $(r=.46, n=136, p<.001)$. In comparison, a lower correlation was found in attention + disorganization with hyperactivity + impulsivity $(r=.28, \quad n=136$, $p=.001$ ). Stieglitz (2011) correlated all WRAADDS scales with those of the CAARS-R (inattention, and hyperactivity/impulsivity) and the ADHD-SR (inattention, hyperactivity, and impulsivity). In most of the cases, the WRAADDS subscales temper control, affective lability, and emotional overreactivity had moderate correlations with the other subscales of these instruments (cf. Table 1). These findings show that emotional dysregulation represents a valid domain.

\section{Divergent validity}

The other aspect of construct validity, the divergent validity, was investigated in a few studies. The objective was to analyse whether emotional dysregulation in ADHD is unrelated to other psychopathological features. Reimherr et al. (2005) examined whether the comorbid subsyndromal symptoms of depression and/or anxiety account for 
Table 1 Convergent validity (correlations) of emotional dysregulation domain with other ADHD scales

\begin{tabular}{|c|c|c|c|c|c|c|}
\hline \multirow[t]{3}{*}{ Study } & \multirow[t]{3}{*}{$\mathrm{ED}^{\mathrm{a}}$ measure } & \multicolumn{5}{|l|}{ Scale } \\
\hline & & \multicolumn{2}{|c|}{ CAARS $^{\mathrm{b}}$} & \multicolumn{3}{|c|}{ ADHS-SR ${ }^{c}$} \\
\hline & & $\mathrm{Ina}^{\mathrm{d}}$ & $\mathrm{Hyp}^{\mathrm{e}} / \mathrm{Imp}^{\mathrm{f}}$ & Ina & Нyp & $\operatorname{Imp}$ \\
\hline \multirow{5}{*}{$\begin{array}{l}\text { Reimherr et al. (2005) } \\
\text { Stieglitz (2011) }\end{array}$} & WRAADDS $^{\mathrm{g}}$ ED & $.48 * * *$ & $.48 * * *$ & - & - & - \\
\hline & WRAADDS & & & & & \\
\hline & Temp $^{\text {h }}$ & $.31 * * *$ & $.53 * * *$ & $.24 * * *$ & $.41 * * *$ & $.43 * * *$ \\
\hline & Affect ${ }^{i}$ & .40 & $.41 * * *$ & $.32 * * *$ & $.33 * * *$ & $.33 * * *$ \\
\hline & Overreact $^{\mathrm{j}}$ & $.36 * * *$ & $.17 * * *$ & $.27 * * *$ & $.08 *$ & $.13 * *$ \\
\hline
\end{tabular}

${ }^{*} p<.10 * * ; p<.01 * * * ; p<.001 ;{ }^{\mathrm{a}}$ emotional dysregulation, ${ }^{\mathrm{b}}$ Conners Adult ADHD Rating Scale, ${ }^{\mathrm{c}}$ ADHD Self-Report, ${ }^{\mathrm{d}}$ inattention, ${ }^{\mathrm{e}}$ hyperactivity, ${ }^{\mathrm{f}}$ impulsivity, ${ }^{\mathrm{g}}$ Wender-Reimherr Adult Attention Disorder Rating Scale, ${ }^{\mathrm{h}}$ temper control, ${ }^{\mathrm{i}}$ affect lability, ${ }^{\mathrm{j}}$ emotional overreactivity

emotional dysregulation in ADHD adults. They used the Hamilton Depression Rating Scale (HAM-D; Hamilton 1967) and the Hamilton Anxiety Rating Scale (HAM-A; Hamilton 1959). Correlations between emotional dysregulation and assessment scores of the WRAADDS and HAM-D $(r=.30, n=170) /$ HAM-A $(r=.31, n=170)$ were moderate, that is, emotional dysregulation does not reflect symptoms of anxiety or depression but is a distinct symptomatology. Corbisiero et al. (2010) and Stieglitz (2011) compared the subscales of the WRAADDS attention, hyperactivity, and impulsivity, and all subscales of the WRAADDS, respectively, with the Eysenck Impulsivity Questionnaire (I7; Eysenck et al. 1990). The two studies were able to show that the subscales of the WRAADDS had very low correlations with the subscales venturesomeness and empathy of I7 $(r=.00-.16$ and $r=$ $-.15-.28$, respectively). Even when the variable "age" was added, the correlations of the subscales of the WRAADDS were very low ( $r=.02-.11$; Stieglitz 2011). Also these findings emphasize the validity of the domain emotional dysregulation. Moreover, they indicate that emotional symptoms constitute an independent psychopathological area of ADHD that can be distinguished from other psychopathological construct.

\section{Measurement of change}

The subscales of the WRAADDS have already been taken to measure changes in the ADHD symptomatology. The sensitivity to measure change of the WRAADDS is comparable with that of ADHD-RS and ADHD-DC, which, however, do not include measures of emotional dysregulation, and the CAARS. In several psychopharmacological studies, the sensitivity to measure change of the emotional dysregulation domain was examined. The results were satisfactory (Reimherr et al. 2005, 2007, 2010; Rösler et al. 2010). Reimherr et al. (2007) found in response to atomoxetine (ATX) similar $p$ values for the WRAADDS and the ADHD-RS $(p<.001$ for the total and the emotional dysregulation score and $p=.002$ for only the total score, respectively), and effect sizes were somewhat larger for the WRAADDS (Cohen's $d=.70-93$ ) in contrast to the ADHD-RS ( $d=.69-.75)$. Reimherr et al. (2010) found a significant positive correlation between change scores, defined as the difference between active treatment and placebo conditions. The correlation of the change scores for emotional dysregulation with attention + disorganization and hyperactivity + impulsivity was over $.88(n=92$, $p<.001)$. In the treatment investigation with methylphenidate (MPH) in adults with ADHD by Rösler et al. (2010), the researchers correlated the score of the Emotional Dysregulation Scale (EDS: temper control, affect lability, and emotional overreactivity) derived from the WRAADDS with the Emotional Lability Scale (ELS) composed of six items of the CAARS Self-Report, Long Form (CAARS-L). At the end of the observation period (at week $24)$, the correlation between ELS and EDS was .81 $(p<.0001)$ in the placebo group and $.67(p<.0001)$ in the group treated with MPH.

\section{Treatment response}

In terms of clinical relevance, not only the classification of the common versus the distinguishable features within the entire spectrum of ADHD symptoms is of importance, but especially the exploration of the extent to which the symptoms of adult ADHD can be influenced by therapeutic interventions. According to the evidence-based guidelines, it is undisputed that psychopharmacological treatment with MPH is actually the method of choice to treat inattention, hyperactivity, and impulsivity in adults with ADHD (NICE 2008; Nutt et al. 2007). This recommendation is corroborated by different meta-analyses demonstrating the significant effect of stimulants and atomoxetine (ATX) on the classical symptom triad (Castells et al. 2011; Faraone et al. 2004; Koesters et al. 2009; Meszaros et al. 2009). In regard 
to the question whether the psychopathology of emotional dysregulation is part of the disorder ADHD or, on the contrary, is related to comorbid conditions or may be a separate disorder all together, it may be of importance to learn more about their therapeutic response to stimulants and ATX. In a multicentre, placebo-controlled study with 596 patients taking ATX, Reimherr et al. (2005) examined the importance of the symptoms of emotional dysregulation. On the one hand, it was demonstrated that about a third of the patients in the sampling who met the psychopathological criteria of the dimension of emotional dysregulation had a higher overall value in the ADHD symptomatology at baseline, a lower response to placebo, and a better response to ATX. On the other hand, it was, among other aspects, concluded that the symptoms of emotional dysregulation showed a similar treatment effect as the classical three ADHD symptom areas. In the measure of emotional dysregulation symptoms, patients on ATX improved at week 10 in contrast to the placebo group improvement. The effect size (Cohen's $d$ ) of the emotional dysregulation domain was the highest $(d=.66$, $p=.001)$ compared with the other domains. In a second study by Reimherr et al. (2007) using MPH this time, these findings were confirmed: the outcome for emotional dysregulation as a function of treatment was with an effect size of .70 in contrast to the higher score of the placebo group. While the study of Reimherr et al. (2007) had a short observation period of 4 weeks, in the study of Rösler et al. (2010) with 359 patients a duration of 24 weeks of treatment with MPH was chosen in order to examine the medium- to long-term response and to study a possible decline in effectivity over time. In this study, the above-mentioned three areas were part of the EDS consisting of the 10 items of the WRAADDS assessing emotional symptoms. A significant decrease in emotional symptoms as early as the 5th week onwards in patients treated with extended release MPH (MPH-ER) was detected. The treatment response was robust over time. There was no evidence of a fading of the MPH-ER effects even after 24 weeks. The MPH-ER treatment group was significantly better than the placebo group $(d=.37)$. The results with the EDS were based on information collected by observer ratings. When the authors of the study used the emotional items of the CAARS-L self-rating version, they found similar results as compared with the WRAADDS-EDS. This means that the positive therapeutic response of MPH-ER on the psychopathology of emotional dysregulation can be detected by self-reports of the patients and by observer rating scales as well. Interestingly, the symptoms of depression and anxiety as defined by the corresponding subscales of the SCL-90-R (Derogatis 1977) did not respond to MPH-ER treatment. In a recent controlled study with 162 adults suffering from ADHD by Retz et al. (2012), these findings were replicated. Patients with ADHD demonstrated a significant improvement in symptoms of emotional dysregulation in favour of MPHER as compared with placebo. Even in this study, symptoms of depression assessed by the Beck Depression Inventory (BDI) did not show a significant treatment response. This might be an argument for the view that the symptoms of emotional dysregulation are not related to comorbid affective disorders (Table 2).

Cognitive-behavioural treatment (CBT) seems to minimize complaints and impairments due to emotional symptoms in adult ADHD (cf. Elsässer et al. 2010; Knouse and Safren 2010; Safren et al. 2005). It is not clear, however, whether the emotional symptoms that respond are a unique and distinct construct rather than reflecting dysphoria, low self-esteem, or self-efficacy co-occurring in ADHD (Skirrow et al. 2009). It is also remarkable that in some psychotherapeutic studies, emotional symptoms are not explicitly defined but are seen as anger, symptoms of anxiety, and depression and are mostly assessed with different non-specific ADHD scales (Bramham et al. 2009; Safren et al. 2005; Stevenson et al. 2002). Safren et al. (2005) proposed among others the two optional modules anger and frustration management as well as communication skills, in which difficulties were treated that overlap with those associated with emotional dysregulation defined by the WRAADDS. Also Bramham et al. (2009) included in their group cognitive-behavioural therapy modules on emotion, the aspects of anger and frustration as well as relationship skills that could in part be associated with emotional dysregulation symptoms. Hesslinger et al. (2002) adapted the dialectal behaviour therapy (DBT) skills training group treatment of Marsha M. Linehan for the treatment for ADHD in adults. This programme applied explicitly emotional regulation skills as well as the group

Table 2 Effect sizes of emotional dysregulation scales measured in psychopharmacological studies

\begin{tabular}{lllll}
\hline Study & Treatment & $N$ & Measure & $\begin{array}{l}\mathrm{ES}^{\mathrm{a}} \\
\mathrm{ED}^{\mathrm{b}}\end{array}$ \\
\hline $\begin{array}{l}\text { Reimherr et al. } \\
(2005)\end{array}$ & ATX $^{\mathrm{c}}$ & 596 & WRAADDS $^{\mathrm{d}}$ & $.66^{* *}$ \\
$\begin{array}{l}\text { Reimherr et al. } \\
(2007)\end{array}$ & $\begin{array}{c}\text { OROS } \\
\text { MPH }\end{array}$ & 47 & WRAADDS & $.70^{* *}$ \\
$\begin{array}{l}\text { Rösler et al. (2010) } \\
\text { Retz et al. (2012) }\end{array}$ & MPH-ER $^{\mathrm{f}}$ & 363 & WRAADDS & $.37^{* * *}$ \\
\hline
\end{tabular}

$* p<.05 ; * * p<.001 ; * * * p<.0001 ;{ }^{a}$ effect size: Cohen's $d$, ${ }^{\mathrm{b}}$ emotional dysregulation in ADHD, ${ }^{\mathrm{c}}$ atomoxetine, ${ }^{\mathrm{d}}$ Wender-Reimherr Adult Attention Disorder Rating Scale, ${ }^{\mathrm{e}}$ osmotic release oral system methylphenidate, $\mathrm{f}$ extended-release methylphenidate, $\mathrm{g}$ affective lability 
therapy of Philipsen et al. (2007). They mentioned in their group psychotherapy emotional regulation to be regarded by patients $(67.7 \%)$ as one of the most helpful programme topics. Rostain and Ramsay (2006) further examined the effects of 6 months of medication combined with CBT. Adults with ADHD receiving combined medication treatment and CBT showed significant reductions in ADHD symptoms assessed with the Brown Attention-Deficit Disorder Scale (BADDS, Brown 1996) observer report. Also, the subscale emotion of the BADDS improved with statistical relevance $(d=.47, N=38, p<.001)$. This subscale is consistent with two subscales (affect lability and temper control) of the WRAADDS (cf. Fig. 1). In the research of Solanto et al. (2008), the effect size of the BADDS (self report) subscale emotion was even very high $(d=.93, n=30, p<.001)$. In contrast with the other subscales of the BADDS in both studies, the effect size of the subscale emotion was the lowest, however. Finally, Virta et al. (2008) treated emotional dysregulation assessed with the BADDS (self report) in their cognitive-behaviourally oriented group rehabilitation programme. The symptoms decreased with an effect size of $d=.30$. After 6 months (follow-up), no significant change of the total BADDS symptoms was found (Salakari et al. 2010). Unfortunately, the authors disregarded the emotional dysregulation symptoms in their follow-up study. In summary, the data on CBT for adult ADHD suggest that psychotherapeutic interventions may play a role in effectively treating this disorder. However, additional randomized controlled studies are needed to elucidate the effects of psychotherapy on the psychopathology of emotional dysregulation. So far, nearly all CBT treatments resulted in large effect sizes $(d=.80)$ on total ADHD symptoms (Knouse and Safren 2010) (Table 3).

Table 3 Effect sizes of emotional dysregulation scales measured in psychotherapy studies

\begin{tabular}{|c|c|c|c|c|}
\hline Study & Treatment & $N$ & Measure & $\begin{array}{l}\mathrm{ES}^{\mathrm{a}} \\
\mathrm{ADHD} \\
\mathrm{ED}^{\mathrm{b}}\end{array}$ \\
\hline $\begin{array}{l}\text { Rostain and } \\
\text { Ramsay } \\
\text { (2006) }\end{array}$ & $\begin{array}{l}\text { Combined treatment: } \\
\text { medication and } \mathrm{CBT}^{\mathrm{d}}\end{array}$ & 38 & $\begin{array}{l}\text { BADDS } \\
(\mathrm{O})^{\mathrm{c}}\end{array}$ & $.47 * *$ \\
\hline $\begin{array}{l}\text { Solanto et al. } \\
\text { (2008) }\end{array}$ & & 30 & $\begin{array}{l}\text { BADDS } \\
(\mathrm{S})^{\mathrm{e}}\end{array}$ & $.93 * *$ \\
\hline $\begin{array}{l}\text { Virta et al. } \\
\text { (2008) }\end{array}$ & $\begin{array}{l}\text { Cognitive-behaviourally } \\
\text { oriented group } \\
\text { rehabilitation }\end{array}$ & 29 & $\begin{array}{l}\text { BADDS } \\
\text { (S) }\end{array}$ & $.30 *$ \\
\hline
\end{tabular}

\section{Conclusions and perspectives}

The clinical picture of ADHD in adulthood is more complex than previously thought. This has been demonstrated by several studies. The three classical domains, inattention, hyperactivity, and impulsivity, display only poorly the complete spectrum of possible symptoms in adults. It seems therefore necessary to expand this range. The debate in recent years and the empirical results of different studies suggest extending the spectrum of the ADHD psychopathology to include the domain of emotional dysregulation, which is, after all, a core feature of adult ADHD as designed by Paul H. Wender (1995). Several studies have shown that the areas of poor temper control, emotional overreactivity, and affect lability are clinically relevant. Not only do these symptoms cause considerable suffering in the patients, but their prevalence is also similar to the three classic symptom areas. Also in the ADHD construct by Barkley (2006) the regulation of emotions plays an important role. The five major constructs in his theory are: inhibition, non-verbal working memory (self-directed sensing, especially visual imagery), verbal working memory (self-directed private speech), reconstitution (generativity, problem-solving, and goal-directed inventiveness), and emotional-motivational self-regulation. Barkley and Murphy (2010) proposed the Emotional Impulsiveness Scale (EIS, self- and other rating scale) to examine emotional dysregulation that the authors define as emotional impulsiveness. The symptoms of emotional impulsiveness to be involved in ADHD according to Barkley and Murphy (2010) are: (1) impatient; (2) quick to anger; (3) easily frustrated; (4) overreact; (5) easily excited; (6) loose temper; (7) touchy/annoyed. The EIS showed in the analyses good psychometric properties: emotional impulsiveness was considered as a single, unitary construct; the self-and other rating scale of the EIS correlated highly with each other, suggesting good external validity; also the association of the scale with measures of functional impairment occurring with ADHD symptoms alluded to external validity. The seven symptoms of emotional impulsiveness were present in a majority of the adults with ADHD, with a significantly greater frequency than in the clinical control group, and the community control group. Also the severity of symptoms of emotional impulsiveness was significantly greater in the patients with ADHD. The study concludes that emotional dysregulation is a significant area of symptom expression in ADHD. Barkley and Fischer (2010) were able to replicate these results in another study evaluating emotional impulsiveness in hyperactive and control children followed into adulthood.

A further central aspect underlining the importance of emotional symptoms, which do not belong to the DSM-IV/ DSM-5 concept of ADHD, is their positive response to 
psychopharmacological treatments with MPH or ATX. In future studies using multivariate methods (e.g. latent class analysis) it might be useful to examine whether there is any one single subtype with predominant symptoms in the field of emotional dysregulation.

Emotional dysregulation symptoms seems to be more frequently in patients diagnosed with combined type ADHD (Reimherr et al. 2005, 2010; Robison et al. 2008). Genetic investigations could also clarify the role of emotional dysregulation in adult ADHD. Robison et al. (2010) used in their study emotional dysregulation as an additional endophenotype to examine genes implicated in ADHD. Eight single nucleotide polymorphisms (SNP) were genotyped. One SNP was significantly associated with emotional dysregulation. The analysis of this SNP showed a trend towards significance when using emotional dysregulation as an ADHD subtype. According to the researchers this suggests that the different symptoms of ADHD might be connected with specific genetic variants. In a recent study Surman et al. (2011) conducted a family risk analysis to clarify the familial relationship between ADHD and deficient emotional self-regulation (DESR) in adults defined from the Barkley Current Behaviour Scale, which is comparable to the domain of emotional dysregulation of the WRAADDS. Six of the eight items of this scale are identical to items of EIS (Barkley and Fischer 2010) mentioned above. Siblings of ADHD patients were at elevated risk to have ADHD irrespective the presence or absence of emotional dysregulation. Emotional dysregulation symptomatology was only elevated among siblings of adults with ADHD and identified DESR. Attention-deficit hyperactivity disorder and DESR cosegregated in siblings. The findings suggest, in accordance with the authors, that emotional dysregulation may be a familial subtype of ADHD. The authors indicated that the results of the study cannot exclude contribution of non-axis-I DSM-IV disorders to risk for emotional dysregulation and cannot determine whether the cosegregation of ADHD in DESR within families is a consequence of genetic or environmental risk factors.

Additionally, symptoms of emotional dysregulation in adult ADHD seem to compromise the severity of the ADHD symptomatology as well as its comorbid disorders (e.g. sleeping problems, somatic complaints, anxiety-tension, oppositional-defiant symptoms) and impairments in important domains of major life activities (Reimherr et al. 2005, 2007, 2010; Robison et al. 2008). Gender differences were examined: Women with ADHD seem furthermore to have a higher level of emotional symptoms. These symptoms would complicate the ADHD symptomatology and may, particularly in women, obscure the diagnosis of ADHD (Robison et al. 2008). Barkley and Murphy (2010) argue that emotional dysregulation makes significant contributions to impairment in numerous forms of major life activities including social and occupational functioning, educational history, driving risk, criminal history, marital satisfaction, parenting stress, and severity of offspring disruptive behaviour disorders. Even more, symptoms of emotional dysregulation contribute to impairments in major life activities beyond those associated with the traditional dimensions (inattention, hyperactivity, and impulsivity) of ADHD symptoms (Barkley and Fischer 2010; Barkley and Murphy 2010).

In conclusion, emotional dysregulation symptoms and scales show not only similar or even higher internal consistencies than other symptoms and subscales of ADHD, but also better interrater reliability. Aspects of emotional dysregulation are further independent dimensions that can be distinguished from other domains of ADHD symptomatology. The prevalence of emotional symptoms in adult ADHD samples is on the same level as the classical ADHD symptoms inattention, hyperactivity, and impulsivity. Finally, emotional symptoms respond to MPH and ATX treatment. The effect sizes of treatment regarding inattention, hyperactivity, impulsivity, and emotional dysregulation are nearly identical. The emotional dysregulation domain seems to be an important part of the psychopathology of adult ADHD and contributes considerably to impairments in most of the domains of major life activities, besides leading to a more severe ADHD symptomatology. The different concepts of ADHD and the various definitions of emotional dysregulation complicate the comparison of studies. A uniform description and definition of symptoms would be appropriate to provide both researchers and clinicians a clue to emotional dysregulation in adult ADHD. DSM-IV/DSM-5 and ICD-10 classify inattention, hyperactivity, and impulsivity as the core symptoms of ADHD without mentioning emotional symptoms. However, the constructs by Wender, Brown, Conners, and Barkley presented here attest a decisive role of the emotional dysregulation domain in the ADHD symptomatology and deserve more respect and consideration in future research on ADHD.

\section{References}

Barkley RA (2006) Attention-deficit hyperactivity disorder: A handbook for diagnosis and treatment. Guilford, New York

Barkley RA, Fischer M (2010) The unique contribution of emotional impulsiveness to impairment in major life activities in hyperactive children as adults. J Am Acad of Child Adolesc Psychiatry 49:503-513

Barkley RA, Murphy KR (2006) Identifying new symptoms for diagnosing ADHD in adulthood. ADHD Rep 14:7-11

Barkley RA, Murphy KR (2010) Deficient emotional self-regulation in adults with attention-deficit/hyperactivity disorder (ADHD): 
the relative contributions of emotional impulsiveness and ADHD symptoms to adaptive impairments in major life activities. J ADHD Relat Disord 4:5-28

Biederman J, Mick E, Faraone SV (2000) Age-dependent decline of symptoms of attention deficit hyperactivity disorder: impact of remission definition and symptom type. Am J Psychiatry 157:816-818

Bramham J, Young S, Bickerdike A, Spain D, McCartan D, Xenitidis K (2009) Evaluation of group cognitive behavioral therapy for adults with ADHD. J Atten Disord 12:434-441

Brown TE (1996) Brown attention deficit disorder scales. The Psychological Corporation, San Antonio

Castells X, Ramos-Quiroga JA, Bosch R, Nogueira M, Casas M (2011) Amphetamines for attention deficit hyperactivity disorder (ADHD) in adults. Cochrane Database Syst Rev 6

Conners CK, Erhard D, Sparrow D (1999) Conners' Adult ADHD Rating Scales (CAARS). Multi-Health Systems, New York

Corbisiero S, Buchli-Kammermann J, Stieglitz RD (2010) Reliability and validity of the Wender-Reimherr-Interview (WRI). An instrument for the diagnostic of the ADHD in adulthood. Z Psychiatr Psychol Psychother 58:323-331

Derogatis LR (1977) SCL-90-R, administration, scoring and procedures. Johns Hopkins University Baltimore MD, (Manual for the revised version)

Elsässer M, Nyberg E, Stieglitz RD (2010) Cognitive-behavioral treatment strategies for adults with ADHD. Z Psychiatr Psychol Psychother 58:35-44

Eysenck S, Daum I, Schugens M, Diehl J (1990) A cross-cultural study of impulsiveness, venturesomeness and empathy. Germany and England. Z Different Diagn Psychol 11:209-213

Faraone SV, Spencer T, Aleardi M, Pagano C, Biederman J (2004) Meta-analysis of the efficacy of methylphenidate for treating adult attention-deficit/hyperactivity disorder. J Clin Psychopharmacol 24:24-29

Faraone SV, Biederman J, Mick E (2006) The age-dependent decline of attention deficit hyperactivity disorder: a meta-analysis of follow-up studies. Psychol Med 36:159-165

Fayyad J, De Graf R, Kessler R, Alonso J, Angermeyer M, Demyttenaere K, De Girolamo G, Haro M, Karam EG, Lara C, Lepine JP, Ormel J, Posada-Villa J, Zaslavsky AM, Jin T (2007) Cross-national prevalence and correlates of adult attention-deficit hyperactivity disorder. Br J Psychiatry 190:402-409

Gibbins C, Weiss M (2007) Clinical recommendations in current practice guidelines for diagnosis and treatment of ADHD in adults. Curr Psychiatry Rep 9:420-426

Hamilton M (1959) The assessment of anxiety states by rating. Br J of Med Psychol 32:50-55

Hamilton M (1967) Development of a rating scale for primary depressive illness. Br J Soc Clin Psychol 6:278-296

Hesslinger B, Tebartz van Elst L, Nyberg E, Dykierek P, Richter H, Berner M, Ebert D (2002) Psychotherapy of attention deficit hyperactivity disorder in adults: a pilot study using a structured skills training program. Eur Arch Psychiatry Clin Neurosci 252:177-184

Knouse LE, Safren SA (2010) Current status of cognitive behavioral therapy for adult attention-deficit hyperactivity disorder. Psychiatric Clin North Am 33:497-509

Koesters M, Becker T, Kilian R, Fegert JM, Weinmann S (2009) Limits of meta-analysis: methylphenidate in the treatment of adult attention-deficit hyperactivity disorder. J Psychopharmacol 25:733-744

Mannuzza S, Klein RG, Bessler A, Malley P, LaPadula M (1993) Adult outcome of hyperactive boys: educational achievement occupational rank, and psychiatric status. Arch Gen Psychiatry 50:565-576
Meszaros A, Czobor P, Balint S, Komlosi S, Simon V, Bitter I (2009) Pharmacotherapy of adult attention deficit hyperactivity disorder (ADHD): a meta-analysis. Int $\mathbf{J}$ Neuropsychopharmacol 12: $1137-1147$

Murphy KR, Gordon M (2006) Assessment of adults with ADHD. In: Barkley RA (ed) Attention-deficit hyperactivity disorder: a handbook for diagnosis and treatment. Guilford, New York, pp 425-450

NICE (2008) Attention deficit hyperactivity disorder: diagnosis and management of ADHD in children, young people and adults. www.nice.org.uk

Nutt DJ, Fone K, Asherson P, Bramble D, Hill P, Matthews K, Morris KA, Santosh P, Sonuga-Barke E, Taylor E, Weiss M, Young S (2007) Evidence-based guidelines for management of attentiondeficit/hyperactivity disorder in adolescents in transition to adult services and in adults: recommendations from the British Association for Psychopharmacology. J Psychopharmacol 21:10-41

Philipsen A, Richter H, Peters J, Alm B, Sobanski E, Colla M, Münzebrock M, Scheel M, Jacob C, Perlov E, Tebartz van Elst L, Hesslinger B (2007) Structured group psychotherapy in adults with attention deficit hyperactivity disorder. Results of an open multicentre study. J Nerv Ment Dis 195:1013-1019

Reimherr FW, Wender PH, Marchant BK, Strong RE, Hedges DW, Preston GA (2003) The Wender-Reimherr Adult Attention Deficit Disorder Scale as a research tool. Poster presented at the 2003 American College of Neuropsychopharmacology Annual Meeting. San Juan, Puerto Rico

Reimherr FW, Marchant BK, Strong RE, Hedges DW, Adler L, Spencer TJ, West SA, Soni P (2005) Emotional dysregulation in adult ADHD and response to atomoxetin. Biol Psychiatry 58:125-131

Reimherr FW, Williams ED, Strong RE, Mestas R, Soni P, Marchant BK (2007) A double-blind, placebo-controlled, crossover study of osmotic release oral system methylphenidate in adults with ADHD with assessment of oppositional and emotional dimensions of the disorder. J Clin Psychiatry 67:93-101

Reimherr FW, Marchant BK, Olson JL, Halls C, Kondo DG, Williams ED, Robison RJ (2010) Emotional dysregulation as a core feature of adult ADHD: its relationship with clinical variables and treatment response in two methylphenidate trials. J ADHD Relat Disord 4:53-64

Retz W, Rösler M, Ose C, Scherag A, Alm B, Philipsen A, Fischer R, Ammer R (2012) Multiscale assessment of treatment efficacy in adults with ADHD: a randomized placebo-controlled, multicentre study with extended-release methylphenidate. World J Biol Psychiatry 13:48-59

Robison RJ, Reimherr FW, Marchant BK, Faraone SV, Adler LA, West SA (2008) Gender differences in 2 clinical trials of adults with attention-deficit/hyperactivity disorder: a retrospective data analysis. J Clin Psychiatry 69:213-221

Robison RJ, Reimherr FW, Marchant BK, Kondo D, Lyon GJ, Olsen J, Christopherson D, Pommerville C, Tuya S, Johnson A, Coon $\mathrm{H}$ (2010) The use of emotional dysregulation as an endophenotype for genetic studies in adults with attention-deficit/hyperactivity disorder. J ADHD Relat Disord 4:29-38

Rösler M (2011) Different psychopathological dimensions in adult ADHD. In: 3rd World Congress on ADHD, vol 2, p 79

Rösler M, Retz W, Retz-Junginger P, Thome J, Supprian T, Nissen T, Stieglitz R-D, Blocher D, Hengesch G, Trott GE (2004) Tools for the diagnosis of attention-deficit/hyperactivity disorder in Adults. Self-rating behaviour questionnaire and diagnostic checklist. Nervenarzt 75:888-895

Rösler M, Retz W, Retz-Junginger P, Stieglitz RD, Kessler H, Reimherr F, Wender PH (2008a) Attention deficit hyperactivity 
disorder in adults. Benchmarking diagnosis using the WenderReimherr adult rating scale. Nervenarzt 79:320-327

Rösler M, Retz-Junginger P, Retz W, Stieglitz RD (2008b) HASE. Homburger ADHS-Skalen für Erwachsene. Hogrefe, Göttingen

Rösler M, Retz W, Fischer R, Ose C, Alm B, Deckert J, Philipsen A, Herpertz S, Ammer R (2010) Twenty-four-week treatment with extended release methylphenidate improves emotional symptoms in adult ADHD. World J Biol Psychiatry 11:709-718

Rostain AL, Ramsay R (2006) A combined treatment approach for adults with ADHD-Results of an open study of 43 patients. J Atten Disord 10:150-159

Safren SV, Otto MW, Sprich S, Winett CL, Wilens TE, Biederman J (2005) Cognitive-behavioral therapy for ADHD in medicationtreated adults with continued symptoms. Beh Res Ther 43:831-842

Salakari A, Virta M, Grönroos N, Chydenius E, Partinen M, Vataja R, Kaski M, Iivanainen (2010) Cognitive-behaviorally-oriented group rehabilitation of adults with ADHD. Results of a 6-month follow-up. J Atten Disord 13:516-523

Schmidt S, Petermann F (2008) Developmental psychopathology of ADHD. Z Psychiatr Psychol Psychother 56:265-274

Skirrow C, McLoughlin G, Kunsi J, Asherson P (2009) Behavioral, neurocognitive and treatment overlap between attention-deficit/ hyperactivity disorder and mood instability. Expert Rev Neurother 9:489-503
Solanto MV, Marks DJ, Mitchell KJ, Wasserstein J, Kofman MD (2008) Development of a new psychosocial treatment for adult ADHD. J Atten Disord 11:728-736

Stevenson CS, Whitmont S, Bornholt L, Livesey D, Stevenson RJ (2002) A cognitive remediation programme for adults with attention deficit hyperacitivity disorder. Aus N Z J Psychiatry 36:610-616

Stieglitz RD (2011) Different psychopathological dimensions in adult ADHD. 3rd World Congress on ADHD 3:94

Stieglitz RD, Rösler M (2006) Diagnosis of attention-deficit/ hyperactivity disorder (ADHD) in adults. Z Psychiatr Psychol Psychother 54:87-98

Stieglitz RD, Nyberg E, Hofecker-Fallahpour M (2012) ADHS im Erwachsenenalter. Hogrefe, Göttingen

Surman CBH, Biederman J, Spencer T, Yorks D, Miller CA, Petty CR, Faraone SV (2011) Deficient emotional self-regulation and adult attention deficit hyperactivity disorder: a family risk analysis. Am J Psychiatry 168:617-623

Virta M, Vedenpää A, Grönroos N, Chydenius M, Partinen M, Vataja R, Kaski M, Iivanainen M (2008) Adults with ADHD benefit from cognitive-behaviorally oriented group rehabilitation. J Atten Disord 12:218-226

Wender PH (1995) Attention deficit hyperactivity disorder in adults. University Press, Oxford 